\title{
Sloshing Impact Response Analysis for Insulation System of LNG CCS Considering Elastic Support Effects of Hull Structures
}

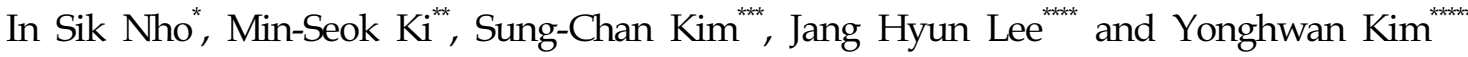 \\ *Department of Naval Architecture \& Ocean Engineering, Chungnam National University, Daejeon, Korea \\ ${ }^{*}$ Korea Research Institute of Ships \& Ocean Engineering, Daejeon, Korea \\ ${ }^{* * *}$ Department of Naval Architecture \& Ocean Engineering, Inha Technical College, Incheon, Korea \\ ${ }^{*}$ Department of Naval Architecture \& Ocean Engineering, Inha University, Incheon, Korea \\ ${ }^{*}$ Department of Naval Architecture \& Ocean Engineering, Seoul National University, Seoul, Korea
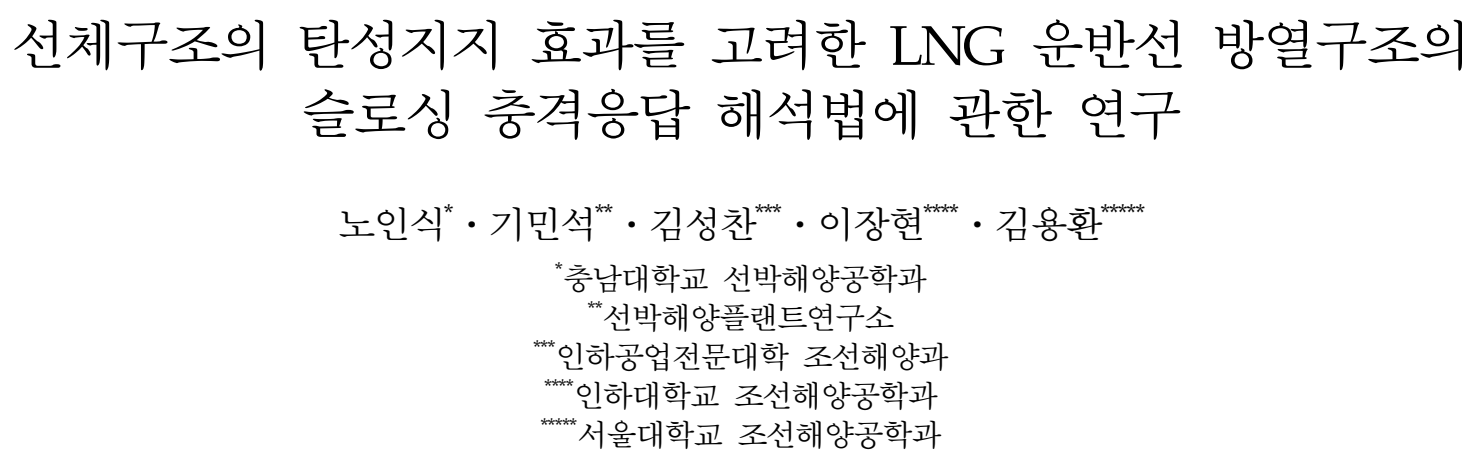

KEY WORDS: Sloshing impact pressure 슬로싱 충격압력; LNG CCS 액화천연가스 격납시스템, Insulation system 방열구조, Transient dynamic response analysis 과도동적응답해석, Triangular response function 삼각형응답함수, Elastic support effects of hull structure 선 체구조의 탄성지지 효과

\begin{abstract}
The sloshing pressure acting on a membrane-type LNG CCS is a typical irregular impact load, and the structural response of a tank system induced by sloshing also shows very complex behavior, including fluid structure interaction. Therefore, it is not easy to accurately estimate the sloshing impact pressures and resulting structural response. Moreover, a huge time consuming process to deal with the enormous pressure data obtained during a model tank test and the following structural analysis would be inevitable. To reduce the computation time for structural analysis, in this study, a rational structural modeling strategy was considered, and a simplified scheme to analyze the dynamic structural responses of an LNG CCS was introduced, which was based on the concept of the linear combination of the triangular response functions obtained by a transient response analysis of structures under unit triangular impact pressure. A structural analysis of a real Mark III membrane type insulation system under the sloshing impact pressure time histories obtained by model tests was performed using the various proposed structural models and simplified analysis scheme. The results were investigated in detail, including the elastic support effects of the hull structure.
\end{abstract}

\section{1. 서 론}

LNG 선박의 CCS(Cargo Containment System) 내부에서 발생하는 슬로싱(Sloshing) 현상 때문에 발생하는 유체 충격력은 멤브레인형 (Membrane type) LNG 선박의 화물창과 방열구조(Insulation system)
를 설계함에 있어서 고려해야 할 가장 중요한 하중 요소 중 하나이 다. 최근의 LNG 운반선과 FLNG(LNG FPSO)의 화물창 대형화 추 세에 따라 방열구조에 작용하는 유체 충격력을 산정하고 이에 대 한 구조응답을 구하기 위하여 다양한 이론적 접근 방법(Graczyk and Moan, 2008)과 수치적 해석 기법(Yum and Yun, 2008)이 제안되

Received 4 April 2017, revised 10 October 2017, accepted 19 October 2017

Corresponding author In Sik Nho +82-42-821-6622, isnho@cnu.ac.kr

It is noted that this paper is revised edition based on proceedings of Computational Structural Engineering Institute of Korea 2011 in Busan. 
고 있다.

하지만 최근 진행되고 있는 여러 정밀한 수치적 해석 기법과 함께 실시되는 모형실험, 실선 계측 등은 부분적으로 좋은 결과 를 보이고는 있지만(Nahm et al, 2007) 유탄성(Hydro-elastic)해석 을 비롯한 수치적 해석 기법(CFD)은 막대한 계산 시간이 필요 한 경우가 많고 모형실험의 경우엔 방대한 계측자료의 처리 방 안에 대한 문제와 축척 효과와 초저온에 기인하는 문제로 인하 여 결과의 정성적 경향은 인정되고 있으나 실제 선체 설계에 직접 적용하기에는 여러 가지 문제점이 남아있어 이에 대한 명 확한 해법이 아직 마련되지 못하고 있다. 그리고 실선 계측은 실험 자체가 어려울 뿐만 아니라 많은 비용과 인력, 소요시간이 들기 때문에 이를 일반화하여 실제 방열구조의 구조설계에 적 용하기에는 현실적으로 문제점들이 남아있다. 따라서 모형실험 또는 실선 계측 데이터를 통해 얻을 수 있는 유체 충격 하중에 대한 구조응답을 충격 압력의 시계열에 의한 시간영역 과도응 답해석으로 구하는 전통적인 방법이 아직 많이 이루어지고 있 고 특히 초기 설계를 위한 개략적인 응답 추정 단계에서 상당 히 합리적인 결과를 보이고 있다. 시간영역 과도응답해석법이 유탄성해석 기법에 비해 계산량이 적은 것은 사실이지만, 모형 실험에서 얻어지는 압력 시계열 자료의 양이 워낙 방대하고, 방 열 패널을 3 차원으로 상세히 모델링하였을 경우에는 자유도 수 역시 상당히 커지므로 방대한 계산시간 때문에 어려움이 있다. 따라서 ABS (2006), Nho et al.(2011a), Nho et al.(2011b), Nho et al.(2012)이 제안한 충격 압력의 시계열을 여러 개의 삼각형 단 위 충격으로 분할하고, 하나의 단위 삼각형 단위 충격에 대한 구조 응답만을 구하여, 이를 중첩하여 전체 충격 압력 시계열에 대한 해를 구하는 삼각형 응답함수를 이용한 간이해석법 (Simplified analysis)은 계산효율 측면에서 주목할 만하다.

본 연구에서는 Fig. 1과 같은 Mark III 멤브레인형 LNG 탱크 방열구조의 유체 충격에 대한 구조 응답 검토 과정에서 선체 구조의 탄성지지 영향을 고려하기 위하여 방열 패널과 그 지지 구조가 되는 선체 화물 탱크 주위를 여러 가지 다양한 범위와 형상으로 함께 모델링하여 정적해석과 시간영역 과도응답해석 을 수행하였다. 시간영역 과도응답해석을 간이해석법과 직접해 석 방법으로 각각 수행하여 적용된 간이해석법의 타당성을 다

\section{Mark III}

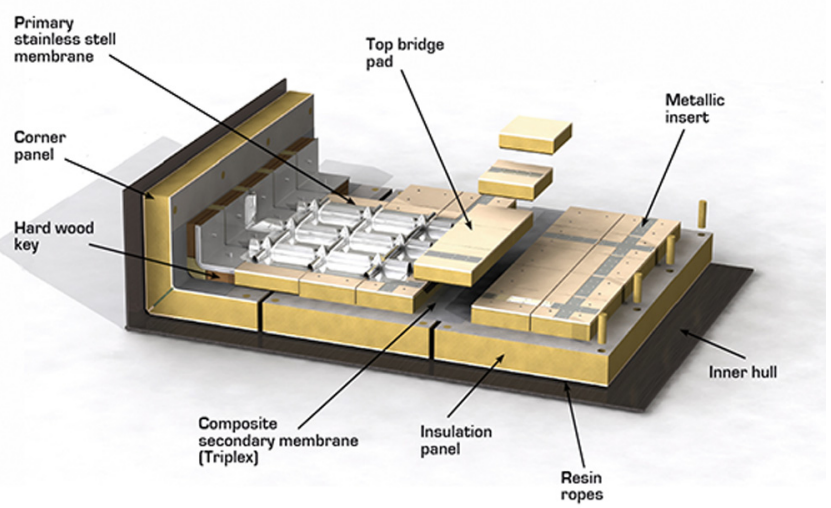

Fig. 1 Schematic view of Mark III membrane type LNG tank (GTT, 2017)
시 한 번 검증하는 한편, 각 해석모델에 대한 정적, 동적 구조해 석 결과를 상호 비교 검토함으로써 해석의 정도를 저하시키지 않는 범위 내에서 해석 영역을 최소한으로 줄여 계산 시간을 절감할 수 있는 가장 합리적인 모델링 방법을 제안하였다. 과도 동적응답해석 과정에서 실제 슬로싱 모형실험으로부터 계측된 압력 시계열 데이터를 실선압력으로 확장하여 적용함으로써 선 체 구조의 탄성지지 영향이 방열구조의 동적 구조응답에 어떻 게 작용하는지 고찰하였다.

\section{2. 방열구조의 구조해석 모델링}

시간영역 과도응답해석법이 CFD법에 기반한 유탄성해석 기 법에 비해 계산량이 적은 것은 사실이지만, 방열 패널을 3 차원 으로 모델링 하였을 경우에는 요소 수가 광장히 방대해져 상당 한 계산량을 필요로 한다. 따라서 본 연구에서는 $\mathrm{LNG} \mathrm{CCS}$ 를 여러 가지 방법으로 모델링하고 이를 이용하여 다양한 구조응 답해석을 수행하여 그 결과를 비교함으로써 합리적이면서도 계 산 시간이 짧은 모델링 방안을 모색하였다. 해석 범위는 Fig. 2 에서 보인 바와 같이 방열 패널이 선측의 종통재(Stringer) 위에 위치한 경우와 일반 보강재 위에 위치한 경우를 비교하여 탄성 지지구조의 강성에 의한 효과를 살펴보고자 한다.

선체와 방열 구조의 모델링 범위는 Mark III 멤브레인형 $160 \mathrm{~K}$ LNGC 탱크 중앙부의 선측 부분으로 국한하였다. 횡늑골 간격 은 $3,200 \mathrm{~mm}$ 이고 탱크의 크기를 고려하여 9 개 횡늑골 범위를 해 석 대상으로 하였다. 이때 좌표축은 방열 패널의 장축 방향(선 체의 종방향)을 $x$, 단축 방향을 $y$, 높이 방향을 $z$-축으로 두었다.

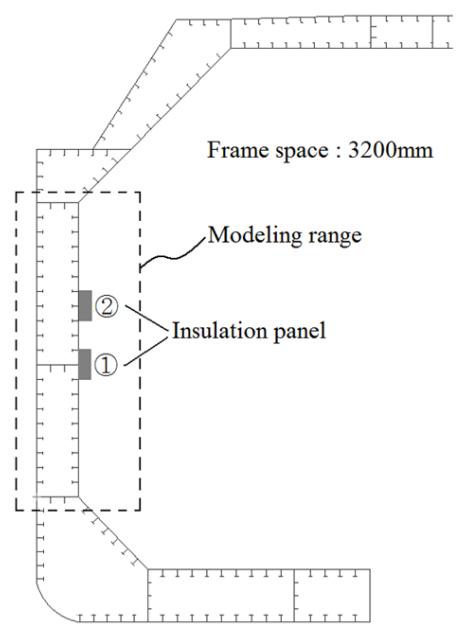

Fig. 2 Modeling range \& position of insulation panel

\section{1 재료 특성치}

Mark III 방열 구조는 주 성분인 Reinforced-PUF(이하 R-PUF) 가 2차방벽인 Triplex를 경계로 2개 층으로 나뉘어져 있고, 받침 대 역할을 하는 Plywood 그리고 선체와 접합을 위한 Mastic으로 구성되어 있다. 각 구성 성분들의 재료특성치를 Table 1에 정리 하였다. 실제로 R-PUF과 Mastic은 등방성 재료, Plywood는 이방 성 재료이고 R-PUF은 점탄성 재료이지만 여기서는 모델링에 따른 결과 비교에 초점을 두어 점탄성 효과는 무시하였다. 
Table 1 Material properties of insulation system

\begin{tabular}{cccc}
\hline \hline & $E[\mathrm{MPa}]$ & $\rho\left[\mathrm{kg} / \mathrm{m}^{3}\right]$ & $\nu$ \\
\hline Mastic & 2,880 & 1,500 & 0.3 \\
Plywood & 8,900 & 710 & 0.17 \\
R-PUF & 84 & 120 & 0.18 \\
Triplex & 13,133 & 2,500 & 0.3 \\
\hline
\end{tabular}

\section{2 해석 모델 및 경계 조건}

LNG 화물창 내부에 작용하는 슬로싱 충격압력은 방열 패널 에 직접 작용하여 변형과 응력을 발생시킬 뿐만 아니라 지지부 가 되는 선체의 변형도 동시에 유발함으로써 방열 구조에 2 차 적인 응력을 발생시킨다(Fig. 3). 결국 방열구조의 구조 응답은 이러한 지지구조의 변형에 무관하게 직접적으로 작용하는 압력 만에 의한 거동과 지지 구조의 변형에 의한 영향의 합으로 나 타나는 것으로 생각할 수 있다(Ki, M.-S., 2011).

이러한 선체 구조의 탄성지지 영향을 고려하기 위하여 R-PUP, Plywood, Mastic로 구성된 방열 패널과지지 선체구조를 함께 모델 링하여 LNG CCS의 동적 구조해석을 수행하였다. 이때, 다음 사항 들을 가정하여 모델링을 단순화하였다.

(1) 슬로싱 충격압력은 1 차방벽인 상면의 주름진 SUS304 박 판(Membrane)을 통하여 방열 패널로 수직방향으로 전달된다. 이때 박판은 주름(Corrugation) 때문에 면내방향 자체 강성이 미 미한 수준이므로 선형 해석이 목적인 본 연구의 구조해석 대상 에서는 제외하였다. 슬로싱 충격에 의한 박판 주름 자체의 손상 문제는 또 다른 연구 주제로 다루어질 수 있을 것이다.

(2) $3,030 \mathrm{~mm}(\mathrm{~L}) \times 990 \mathrm{~mm}(\mathrm{~B}) \times 300 \mathrm{~mm}(\mathrm{H})$ 크기인 표준 방열 패널들은 각각의 사이에 약간의 간격을 두고 탱크벽에 나란히 부착되며, 이 간격은 연성 PUP에 의해 메워진다. 따라서 방열 패널들 사이에서 발생되는 수평방향 변위의 상호작용은 무시할 만한 것으로 간주하고 하나의 패널만 모델링 범위에 포함시켜 해석한다.

(3) Triplex는 두께 $1 \mathrm{~mm}$ 의 매우 얇은 박판이며 실제 시 계산 에서도 방열 패널 전체의 강성과 구조 거동에 미치는 영향이 미미함을 확인하였으므로 모델링에서 제외하였다.

선체 구조의 모델링 범위에 따라 지지부의 강성이 달라질 수 있고 방열 구조의 응답 또한 이에 따라 변화할 수 있기 때문에 선체 구조의 모델링 범위를 달리하여 Fig. 4 와 같은 여러 가지 경 우에 대한 정, 동적해석을 수행하여 그 결과를 비교하고 그 영향 을 고찰하였다. 여기서, (a)는 방열 패널 자체만의 모델링이다. 하 단부를 고정하여 선체의 탄성지지 효과를 배제한 결과를 도출하 여 비교의 기준으로 삼았다. 이때 방열 패널의 요소분할 크기는 $25 \times 25(\mathrm{~mm})$ 이다. 나머지 8 개 모델링들의 특성은 다음과 같다.

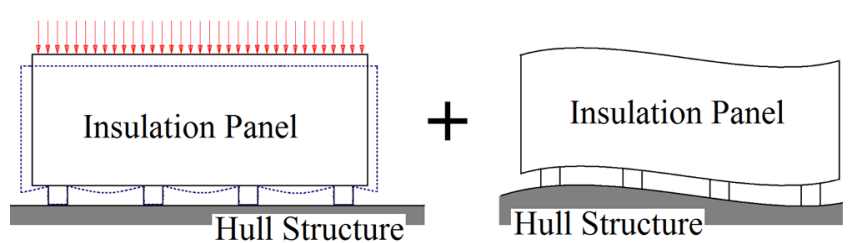

Fig. 3 Structural response of insulation system

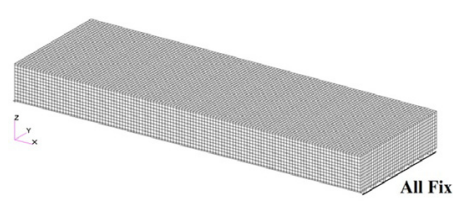

(a) Model for insulation panel alone without hull structures

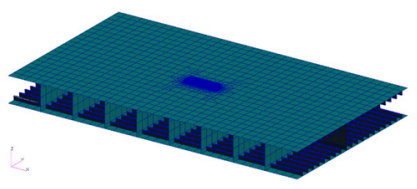

(b) 9 Frame full model

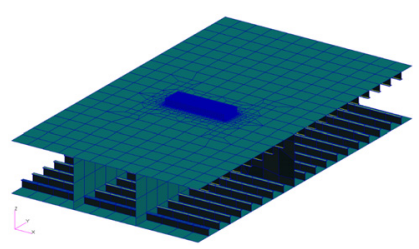

(d) 3 Frame space model

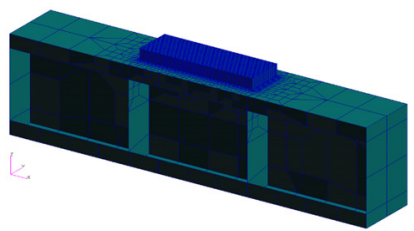

(f) 3 Frame, 2 stiffener space model

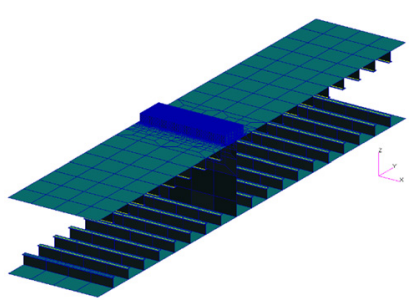

(h) 1 Frame space model

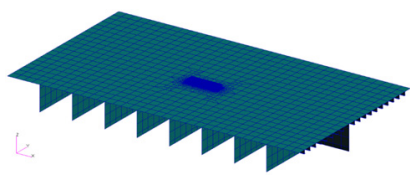

(c) 9 Frame - non outer plate full model

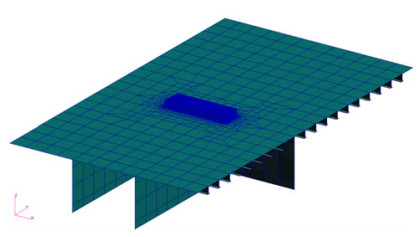

(e) 3 Frame space - non outer plate model

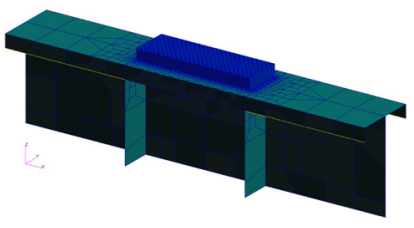

(g) 3 Frame, 2 stiffener space non outer plate Model

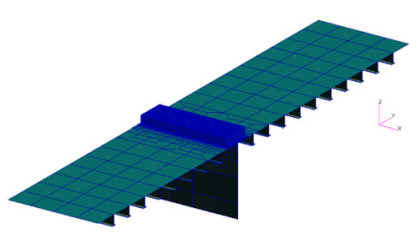

(i) 1 Frame space - non outer plate model
Fig. 4 Modeling cases according to hull modeling range

- Modeling (b) : 선측의 9개 횡늑골 전체를 모델링

- Modeling (c) : (b)에서 외판을 범위에서 제외하고 경계조건 으로 대체

- Modeling (d) : 3개 횡늑골 모델링

- Modeling (e) : (d)에서 외판 제외

- Modeling (f) : 3개 횡늑골을 모델링하였지만 횡 방향으로 두 보강재 간격만을 모델링

- Modeling (g) : (f)에서 외판 제외

- Modeling (h) : 길이 방향으로 1 개 횡늑골 범위, 대신 횡 방 향으로 18 보강재 간격을 모델링

- Modeling (i) : (h)에서 외판 제외 
Table 2 Maximum static stress components of unit pressure in each FE model

[unit : Pa]

\begin{tabular}{|c|c|c|c|c|c|c|c|c|c|c|}
\hline $\begin{array}{c}\text { Stress } \\
\text { components }\end{array}$ & $\begin{array}{l}\text { Panel position } \\
\text { in Fig. } 2\end{array}$ & (a) & (b) & (c) & (d) & (e) & (f) & (g) & (h) & (i) \\
\hline \multirow{2}{*}{$\sigma_{x}$} & (1) & \multirow{2}{*}{-1.484} & -1.729 & -1.664 & -1.722 & -1.664 & -1.673 & -1.672 & -1.727 & -1.722 \\
\hline & (2) & & -2.365 & -2.336 & -2.344 & -2.315 & -2.327 & -2.296 & -1.838 & -1.838 \\
\hline \multirow{2}{*}{$\sigma_{y}$} & (1) & \multirow{2}{*}{16.01} & 32.12 & 32.63 & 32.43 & 32.633 & 32.371 & 32.4 & 37.896 & 37.917 \\
\hline & (2) & & 31.072 & 31.498 & 31.069 & 31.333 & 31.32 & 31.109 & 38.036 & 38.036 \\
\hline \multirow{2}{*}{$\sigma_{z}$} & (1) & \multirow{2}{*}{-0.602} & -0.834 & -0.831 & -0.834 & -0.831 & -0.83 & -0.827 & -0.89 & -0.887 \\
\hline & (2) & & -0.983 & -0.98 & -0.981 & -0.977 & -0.962 & -0.96 & -0.1 & -0.1 \\
\hline \multirow[b]{2}{*}{$\tau_{x y}$} & (1) & \multirow{2}{*}{-0.711} & -0.999 & -1.013 & -0.999 & -0.101 & -1.009 & -1.009 & -1.121 & -1.111 \\
\hline & (2) & & -1.323 & -1.319 & -1.327 & -1.317 & -1.286 & -1.287 & -1.43 & -1.43 \\
\hline \multirow[b]{2}{*}{$\tau_{y z}$} & (1) & \multirow{2}{*}{-0.526} & -0.686 & -0.677 & -0.685 & -0.677 & -0.674 & -0.674 & -0.721 & -0.719 \\
\hline & (2) & & -0.817 & -0.813 & -0.813 & -0.809 & -0.804 & -0.799 & -0.774 & -0.774 \\
\hline \multirow[b]{2}{*}{$\tau_{z x}$} & (1) & \multirow{2}{*}{-0.017} & 0.003 & 0.007 & 0.003 & 0.006 & 0.004 & 0.004 & 0.006 & 0.006 \\
\hline & (2) & & -0.036 & -0.035 & -0.035 & -0.033 & -0.037 & -0.034 & 0.006 & 0.006 \\
\hline
\end{tabular}

이때 (b), (d), (h)의 선체 측면부는 고정단으로, (c), (e), (i)는 선체 측면부와 하부를 고정단으로 하여 외판을 대체하였다. 그 리고 (f)는 다른 해석 모델과 달리 Inner hull의 사이드를 높이 방향으로 거동할 수 있게 하였다. (h)는 선체 하단을 고정단으 로 하여 외판을 대체하였다.

\section{3 정적 해석 결과의 고찰}

Fig. 2에서 보인 바와 같이 방열 패널이 선측의 종통재 (Stringer) 또는 일반 보강재 위의 2가지 위치, 8 가지 모델링 범 위와 방열 패널 자체 모델 즉, 17 가지 해석 모델에 대하여 정적 해석을 수행하고 결과를 고찰하였다. 하중조건은 모든 경우에 동일하게 $1(\mathrm{~Pa})$ 의 정적 단위 압력을 방열 패널의 표면에 작용하 였다.

먼저 최대 응력이 나타나는 Plywood 하부 Mastic과의 접점에서 계산된 응력을 방열 패널 자체만을 모델링 한 경우와 비교하여 각 성분별로 Table 2 에 정리하였다. 대체로 방열 패널의 폭 방향 응력성분 $\sigma_{y}$ 가 압도적임을 알 수 있으므로 이 성분을 기준으로 결과의 정확도를 고찰한다. 선체 강성을 고려하게 되면 방열 패널 만을 모델링하여 하부를 고정으로 간주한 경우인 (a) 보다 거의 2 배 정도 큰 응력이 작용함을 확인할 수 있다. 이것은 탄성지지부 의 변형에 따른 응력 성분이 방열 패널 자체 변형의 영향과 거의 대등한 수준임을 의미한다. 그리고, (h), (i)를 제외한 모든 경우에서 서 비교적 유사한 크기의 응력이 작용함을 확인할 수 있다. (h), (i)가 다른 모델링 경우와 차이를 보이는 이유는 선체 모델링 범위 가 너무 좁아 방열 패널에 인접한 선체 사이드의 경계조건이 높이 방향 거동을 제한하기 때문인 것으로 보인다. 이는 높이 방향 거동 이 자유로운 (f), (g)에 대한 결과를 통해 재확인 할 수 있다. 그리고 외판을 모델링한 경우와 이를 경계조건으로 대체한 경우 유사한 결과를 보이고 있다. 대체로 길이 방향으로 방열 패널 길이의 3 배 이상의 범위를 모델링하면 비교적 합리적인 결과가 도출됨을 확인 할 수 있다.

실제 유체 충격력은 하나의 방열 패널이 아닌 이웃 방열 패널 표면에도 동시에 작용하기 때문에 이 영향을 고려한다면 더 정
Table 3 Comparison of maximum stress levels under unit uniform pressure

\begin{tabular}{ccc}
\hline \hline $\begin{array}{c}\text { Modeling (c) } \\
\text { position (1) }\end{array}$ & $\begin{array}{c}\text { Pressure acting on } \\
\text { insulation panel }\end{array}$ & $\begin{array}{c}\text { Pressure acting on all } \\
\text { tank surface }\end{array}$ \\
\hline$\sigma_{y}$ & $32.6[\mathrm{~Pa}]$ & $35.0[\mathrm{~Pa}]$ \\
\hline
\end{tabular}

확한 해석 결과를 얻을 수 있을 것으로 보인다. 즉 선체지지 구 조의 변형에 따른 영향은 방열 패널 자체에 작용하는 압력 외 에 나머지 주위 패널에 작용하는 압력 역시 고려되어야 한다는 의미이다. 이 영향을 살펴보기 위하여 모델 (b)의 패널 위치 (1) 에서 하나의 방열 패널에만 압력을 작용시킨 경우와 나머지 표 면 전체에 압력을 작용시킨 경우의 응력을 비교해 본 결과, Table 3에서 보는 것처럼 약 $7 \%$ 정도 응력 크기가 증가하는 것 을 확인할 수 있다. 즉, 패널의 구조응답에 있어서 대상 패널 자 체에 직접 작용하는 압력의 영향이 그 주변에 작용하는 압력 성분에 비해 압도적으로 크다는 것을 의미한다. 또한 실제 슬로 싱 충격압력은 대체로 매우 국부적인 면적에 집중되어 작용하 므로 전체적인 면적보다는 패널 하나에 집중적으로 작용하는 것으로 가정하는 것이 더 타당할 수 있다. 이것은 이웃 방열 패 널 사이의 구조적 상호작용은 그다지 크지 않을 것으로 판단한 2.2절의 (2) 가정과 함께 본 연구에서 제시하는 방열 구조의 국 부적 모델링 기법에 대한 근거가 되며, 특히 $\mathrm{CCS}$ 의 초기설계 단계에서는 큰 문제없이 적용 가능함을 입증하고 있다.

\section{4 동적 해석 및 결과 고찰}

정적해석 결과를 고려하여 전체 모델링 (b)와 부분 모델이면서도 비교적 합리적인 결과를 주는 것으로 판단되는 $(\mathrm{d}),(\mathrm{g})$ 등 3 가지 모델링에 대해 과도동적응답해석(Transient dynamic response analysis)을 수행하였다. Fig. 5에서 보는 바와 같이 가장 단순한 이등변 삼각형 형태(Skewness parameter=1)의 단위충격압력을 적용 하였다. 일반적으로 충격하중에 대한 구조물의 응답 특성은 구조물 고유진동 주기에 대한 하중 지속시간의 상대적인 비율에 따라 크게 


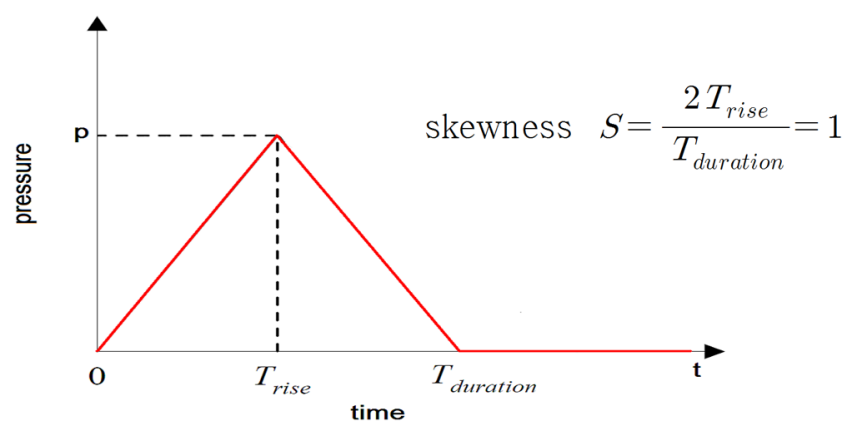

Fig. 5 Triangular impulse

Table 4 Maximum displacements according to duration time of impulse

[unit : $\times 10^{-9} \mathrm{~m}$ ]

\begin{tabular}{cccc}
\hline$T_{\text {duration }}$ Model & (b) & $(\mathrm{d})$ & $(\mathrm{g})$ \\
\hline $4 T_{n}$ & 2.001 & 0.554 & 1.790 \\
$2 T_{n}$ & 3.551 & 0.862 & 2.924 \\
$T_{n}$ & 5.090 & 4.378 & 4.372 \\
$T_{n} / 2$ & 9.362 & 9.250 & 9.249 \\
$T_{n} / 4$ & 14.293 & 14.286 & 14.286 \\
$T_{n} / 8$ & 15.082 & 15.082 & 15.082 \\
$T_{n} / 16$ & 15.107 & 15.107 & 15.107 \\
\hline
\end{tabular}

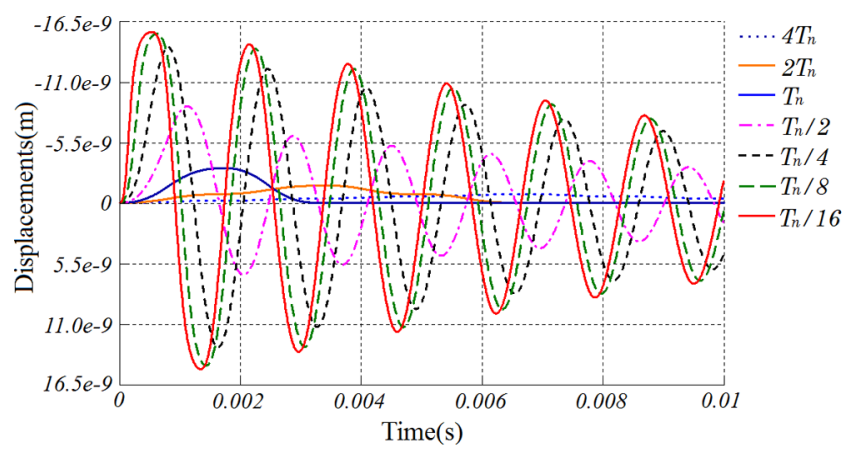

Fig. 6 Time histories of displacements at top surface of insulation panel in model (b)

달라지므로(Nho et al., 2010) 본 연구에서도 단위충격압력의 작용 시간을 방열 패널 자체의 1 차 고유진동주기 $T_{n}$ 에 대한 상대적인 크기로 나타내어 준정적 응답과 충격 응답 범위를 아우를 수 있는 $4 T_{n} \sim T_{n} / 16$ 까지 7단계로 구분하여 해석하고 결과를 검토하였다.

가장 큰 변형이 발생하는 방열 패널 상단 모서리 절점에서의 수직 변형을 정리한 결과를 Table 4에 보였으며 가장 큰 모델인 (b)의 시간이력을 Fig. 6에 나타내었다. 최대 변위는 작용시간이 길 때 차이를 보이다가 작용시간이 짧아질수록 비슷한 크기로 수렴됨을 확인할 수 있다. 이는 Nho et al.(2010)이 보인 바와 같 이 충격에 대한 구조응답이 작용하중의 역적에 의존한다는 일 반적 논리가 적용됨을 나타내고 있다. 이상 선체 강성을 고려한 방열 구조에 대한 구조응답결과를 비교하였을 때, 충격압력의
작용시간이 짧아질수록 전체 모델인 (b)와 부분 모델인 (d), (g) 의 결과가 근접하고 있어 두 부분 모델의 타당성을 확인할 수 있다. 즉 $(\mathrm{g})$ 만으로도 효율적이고 정확한 계산이 가능한 것으로 판단되며 따라서 이후의 해석은 모델링 $(\mathrm{g})$ 로 수행한다.

결론적으로 방열 패널의 거동은 선체의 탄성지지 영향을 크 게 받지만 선측 구조의 전체적인 강성 분포의 영향보다는 패널 이 부착된 부분의 국부적 영향으로 한정됨을 알 수 있으며 따 라서 유한요소해석 모델링의 범위를 방열 패널 부근의 선체구 조만을 모델링하여도 충분한 해석 정도를 확보할 수 있음을 보 여주고 있다.

\section{LNG 탱크 방열구조의 과도응답해석}

유체 충격력을 받는 LNG 탱크 방열 구조의 과도응답해석을 손쉽게 하기 위해 Nho et al.(2011a)에서 제안한 간이해석법을 이용하여 실제 Mark III 방열 구조를 대상으로 유체 충격압력 시계열에 대한 과도응답해석을 수행하고 그 결과를 검토하였다. 대형 모델에 대한 과도응답해석인 경우 간이 응답해석법은 해 석 정도는 거의 그대로 유지하면서 해석시간은 거의 $1 / 100$ 수준 으로 대폭 절감할 수 있음을 보인 바 있다.

\section{1 삼각형 응답함수를 이용한 간이해석법}

먼저 일반적인 형태의 압력 시계열은 Fig. 7에 보인 바와 같 이 짧은 주기의 삼각형 단위 충격압력들의 합으로 표현할 수 있다.

$$
p(t)=\sum_{i=1}^{n} p_{i} \cdot p_{N}^{i}(t)
$$

여기서, $p_{i}$ 는 시간 $t=t_{i}$ 에서 충격 압력의 크기, $\Delta t$ 는 시간 간격 의 크기이다. $p_{N}^{i}(t)$ 는 Fig. 8 에 보인 단위 삼각형 단위 충격압력 이며 다음 식으로 나타낼 수 있다.

$$
p_{N}^{i}(t)=\left[\begin{array}{cc}
\frac{1}{\Delta t}\left(t_{i}-t\right) & \text { when } t_{i-1} \leq t \leq t_{i} \\
1-\frac{1}{\Delta t}\left(t-t_{i}\right) & \text { when } t_{i} \leq t \leq t_{i+1} \\
0 & \text { elsewhere }
\end{array}\right]
$$

삼각형 응답함수(Triangular response function) $L_{i}(t)$ 는 Fig. 9의 삼각형 단위 충격압력 $p_{N}^{i}(t)$ 에 대한 구조 응답의 시계열로 정 의 할 수 있으며, 식 (1)의 일반적인 형태의 압력 시계열에 대한 구조물의 응답 시계열 $R(t)$ 는 삼각형 응답함수들의 합으로 다 음과 같이 나타낼 수 있다.

$$
R(t)=\sum_{i=1}^{n} p_{i} \cdot L_{i}(t)
$$

Nho et al.(2011a) 은 이미 LNG CCS 방열 구조 자체의 동적 응답을 이 삼각형 응답함수를 이용한 간이 과도응답 해석법을 적용하여 구하고, 직접 해석법에 의한 결과를 서로 비교하여 고 


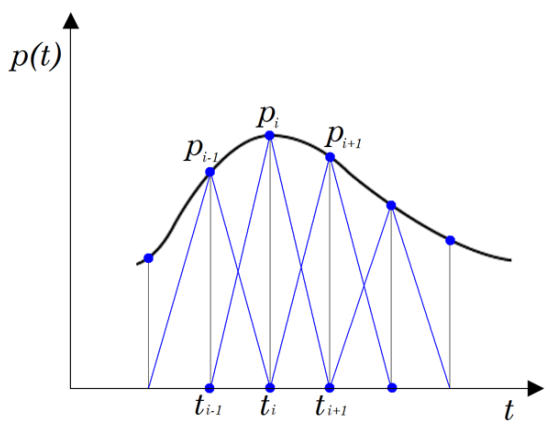

Fig. 7 Decomposition of a pressure time history by unit triangular impulses

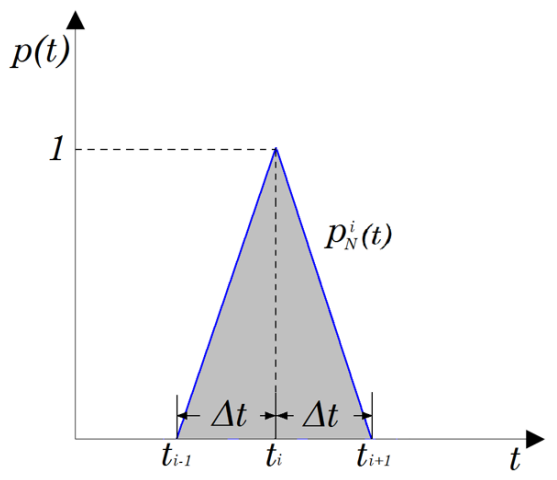

Fig. 8 Unit triangular impulse

찰함으로써 타당성을 확인한 바 있다.

\section{2 간이해석법에 의한 방열구조의 과도응답해석}

$1 / 50$ (Scaling ratio $\lambda=50$ ) 모형실험(20\% Filling level)을 통해 얻어진 탱크 유체 충격압력의 시계열 중 일부를 이용하여 실제 크기의 LNG CCS 방열 패널에 대해 간이 과도응답해석을 수행 하였다. 모형실험의 계측자료 중에서 부분적으로 압력의 피크 치가 가장 크게 나타나는 구간의 시계열을 고려하였다(Fig. 9).

모형실험은 축척 모형을 사용해야하기 때문에 기하학적 상사 성과 함께 재료적 시간적 축척효과를 합리적으로 고려해야 하 지만 슬로싱 현상에 관련된 인자들의 상호 관계가 워낙 복잡하 기 때문에 모형탱크에서 계측된 물리량들을 실선 Scale로 변환 하는 과정에서 관련된 모든 무차원 계수들을 동일하게 유지하
는 것은 불가능하다. 본 연구에서는 모형실험에서 계측된 자료 를 실선 스케일로 확장하기 위해 비압축성 유동에서 일반적으 로 사용되고 있는 다음과 같은 Froude 축척법칙을 적용하였다.

$$
\begin{aligned}
& p_{f}=\lambda \frac{\rho_{f}}{\rho_{m}} p_{m}, \quad \lambda=\frac{L_{f}}{L_{m}} \\
& \Delta t_{f}=\sqrt{\lambda} \Delta t_{m}
\end{aligned}
$$

여기서,

$p_{m}, p_{f}$ : 실험모형과 실선 탱크에서 압력,

$L_{m}, L_{f}$ : 실험모형과 실선 탱크의 길이,

$\rho_{m}, \rho_{f}$ : 실험모형과 실선 탱크에서 유체밀도,

$\Delta t_{m}, \Delta t_{f}$ : 실험모형과 실선 탱크에서 Sampling 주기.

이때, 모형실험의 압력 샘플링 주기는 0.0001 초(샘플링 주파 수 $10 \mathrm{kHz}$ )이므로 Froude 축척법칙을 적용하여 실선 탱크에서 샘플링 주기 $\Delta t_{f}$ 를 결정할 수 있고, 이 값을 Fig. 9에 보인 단위 삼각형 단위 충격압력의 시간 증분 $\Delta t$ 로 두고 해석한다.

먼저 시간 증분의 크기를 $\Delta t_{f} / 20$ 로 하여 삼각형응답함수 $L_{i}(t)$ 를 구한 다음, 이를 이용하여 방열 패널 자체만의 모델링 인 Fig. 4 (a) 및 선체 포함한 모델링 (g) 각각에 대하여 간이 과 도응답해석을 수행하였다. 또한 직접계산에 의한 과도응답해석, 준정적 해석을 수행하고 가장 큰 변위가 발생되는 패널 상면 부의 수직방향 변위 시계열들을 Fig. 10에서 상호 비교하여 나 타내었다. 먼저 Fig. 10(a)는 선체의 탄성지지 효과를 감안한 모 델 $(\mathrm{g})$ 의 동적 거동은 방열 패널 자체만의 모델링 (a)의 결과에 비해 최대치가 2 배 이상으로 현저하게 커지며, 이어지는 충격에 의한 과도 응답도 상당 시간 지속되는 등 확연한 차이가 있음 을 보이고 있다. 이는 선체 구조의 탄성지지 효과를 고려하지 않고 방열 패널 자체 모델만으로 하면을 구속하여 해석하는 방 식을 택하는 경우, 슬로싱 충격압력에 기인하는 패널의 동적구 조 응답을 과소 평가할 수 있음을 의미한다. Fig. 10(b)에 선체 의 탄성지지 강성을 고려한 모델링 $(\mathrm{g})$ 의 직접해석 결과와 간이 해석 결과를 비교하였다. 두 해석 방법의 차이는 거의 보이지 않을 정도로 일치하기 때문에 간이 동적해석법의 정도와 적용 의 타당성을 다시 한 번 확인할 수 있다.
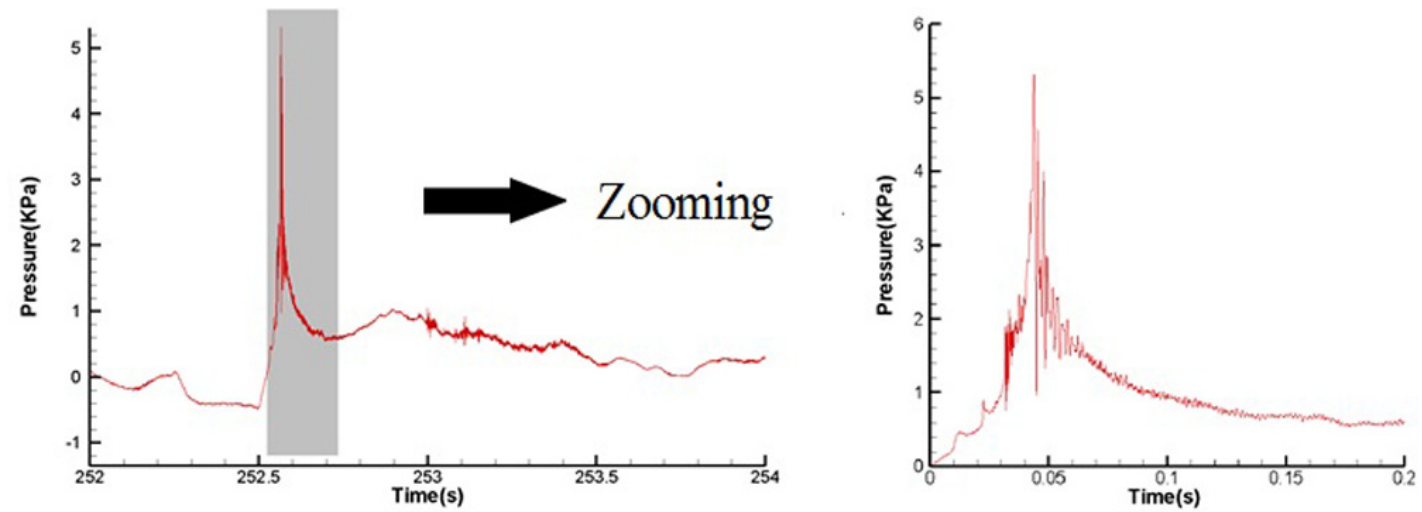

Fig. 9 Selection of pressure time history of sloshing model test 


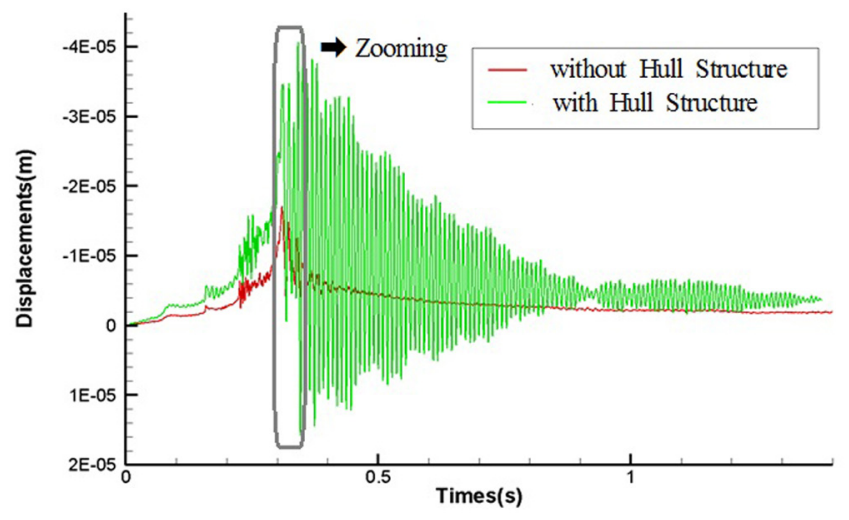

(a) Comparison of all solutions

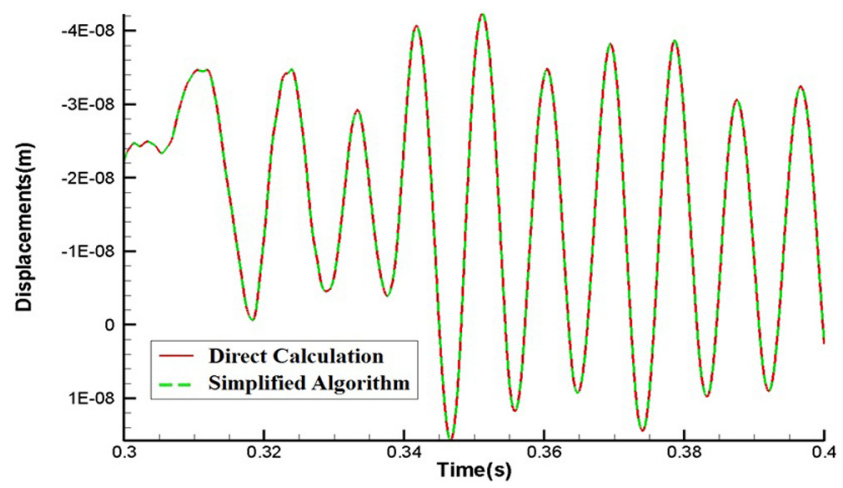

(b) Displacement time history with model (g) including hull structure

Fig. 10 Comparison of displacement time histories

\section{4. 결 론}

Mark III 멤브레인형 LNG 탱크 방열구조의 슬로싱에 의한 유 체충격 응답을 간편하게 해석하기 위하여 화물창의 선측 구조 를 여러 가지 방법으로 모델링하고 이에 대한 구조해석 결과를 비교 검토함으로써 다음과 같은 결론을 제시하였다.

(1) 선체 강성을 고려하는 경우, 최대 압력 발생 이후로 탄성 지지 효과로 인하여 방열 패널 만의 거동에 비해 더 큰 과도 동 적 거동을 나타내는 것을 확인하였다. 따라서 방열 구조의 합리 적인 유체 충격응답 해석을 위해서는 방열구조 지지부의 탄성 지지 효과에 대한 고려가 반드시 필요할 것으로 사료된다.

(2) 방열 패널의 구조거동은 선체의 탄성지지 영향을 크게 받 지만 선측 구조의 전체적인 강성 분포 영향보다는 방열 패널이 부착된 위치의 국부적 영향으로 한정됨이 밝혀졌으며, 따라서 유한요소해석 모델링의 범위를 방열 패널 부근의 선체구조만을 모델링하여도 충분한 정도를 확보할 수 있음을 확인할 수 있다. 이는 최대 압력이 작용하는 지점 주위로 모델링 범위를 축소시 킴으로써 해석에 대한 노력을 상당히 줄일 수 있음을 의미한다.

(3) 슬로싱에 의한 $\mathrm{CCS}$ 의 동적 충격응답 거동을 추정하기 위 하여 간이 응답 해석법을 적용하였다. $1 / 50$ 축척 모형탱크 실험 에서 얻어진 압력 시계열에 대한 동적 응답해석 결과를 검토함 으로써 간이해석법의 정확성과 타당성을 확인하였다.

(4) 삼각형 응답함수를 이용한 간이 과도응답 해석법으로도
짧은 시간 안에 정확한 동적응답계산이 가능하기 때문에 슬로 싱에 대한 단열구조의 구조안전성을 평가할 때 정밀 유탄성 해 석기법을 적용하기 전 단계에서 모형시험에서 얻어진 방대한 압력시간이력의 계측 자료 중에서 관심 대상 구간을 직접 선별 하는 수단으로서 그 효율성을 발휘할 수 있을 것으로 판단된다.

$$
\text { 후 기 }
$$

이 논문은 지식경제부 산업원천기술개발사업인 "LNG 관련 선박 또는 해양구조물의 탱크 설계를 위한 슬로싱 해석 기술 개발 및 관련 인프라 구축(10033656)"과제와 충남대학교 자체연 구과제의 지원으로 수행된 연구 결과의 일부입니다.

\section{References}

American Bureau of Shippng(ABS), 2006. Guidance Note on Strength Assesment of Membrane-Type LNG Containment Systems under Sloshing Loads.

Graczyk, M., Moan, T., 2008. A Probabilistic Assessment of Design Sloshing Pressure Time Histories in LNG Tanks. Ocean Engineering, 35, 834-855.

Gaztransport and Technigaz(GTT), 2017. MARK III System's Original Design, Available at http://www.gtt.fr/

Ki, M.-S., 2011. A study on Sloshing Impact Response Analysis of LNG CCS, M.S. Thesis of Chungnam National University.

Nahm, J.O., Kang, H.D., Chung, J.Y., Kwon, S.H., Choi, H.-S., 2007. An Experimental Study on Slamming Phenomenon by Forced Impact. Journal of Ocean Engineering and Technology, 21(1), 40-44.

Nho, I.S., Lee, J.M., Yeom, C.W., 2010. A Fundamental Study for Time History Modeling of Fluid Impact Pressure. Journal of the Society of Naval Architecture of Korea, 47(2), 242-247.

Nho, I.S., Ki, M.S., Kim, S.C., 2011a. "A Study on Simplified Sloshing Impact Response Analysis for Membrane-Type LNG Cargo Containment System," Journal of the society of Naval Architecture of Korea, Vol 48(5), 451-456.

Nho, I.S., Ki, M.S., Lee, J.M., Kim, S.C., 2011b. A Study on the Sloshing Impact Response Analysis for the Insulation System of Membrane Type LNG Cargo Containment System, Proceeding of 2011 Computational Structural Engineering Annual Conference, Busan

Nho, I.S., Ki, M.S., Yun, Y.M., and Kim, S.C., 2012, "Sloshing Impact Response Analysis for Insulation System of Mark III type LNG Cargo Containment System," Proceedings of the 26th Asian-Pacific Technical Exchange and Advisory Meeting on Marine Structure, Fukuoka, JAPAN, TEAM 2012.

Yum, D.J., Yoon, B.S., 2008. Numerical Simulation of Slamming Phenomena during Water Entry of 2-D Wedges. Journal of the Society of Naval Architects of Korea, 45(5), 477-486. 